\title{
Successful conservative treatment of a caesarean scar twin pregnancy with systemically administered methotrexate and subsequent uterine artery embolization: a rare case report
}

\author{
Shanthi K. Elango, K. Nevetha*, Aruna
}

Department of Obstetrics \& Gynaecology, Government RSRM Lying in Hospital, Chennai, Tamil Nadu, India

Received: 25 October 2021

Revised: 21 January 2022

Accepted: 24 January 2022

*Correspondence:

Dr. K Nevetha,

E-mail: nevethajc@gmail.com

Copyright: () the author(s), publisher and licensee Medip Academy. This is an open-access article distributed under the terms of the Creative Commons Attribution Non-Commercial License, which permits unrestricted non-commercial use, distribution, and reproduction in any medium, provided the original work is properly cited.

\begin{abstract}
Caesarean scar pregnancy is a very rare form of ectopic pregnancy. It complicates approximately 1 in 2200 pregnancies. However, it is becoming increasingly more frequent with the increasing number of caesarean sections performed each year. The recommended approach to treatment is therapeutic termination of pregnancy at the time of recognition. In this article, we present a case of caesarean scar pregnancy managed expectantly with Methotrexate and uterine Artery Embolization. We reported a case of 30 years old female, gravida 5, para1, live 1, abortion 3 with a previous history of caesarean section with GA of 8w5d/DCDA twin was admitted in view of low implantation of gestational sacs in lower uterine corpus. Trans vaginal ultrasound done and diagnosis of caesarean scar twin pregnancy was made. She was treated with Methotrexate $50 \mathrm{mg}$ intramuscularly along with uterine artery embolization and follow up with beta HCG levels. Post embolization sac size was reduced and falling level of beta HCG values. Patient was discharged and followup with beta HCG level weekly. It is important for obstetrician and radiologist managing women with risk factor for a scar ectopic pregnancy to maintain a high index of suspicion during follow up. Failure to diagnose and initiate prompt management may lead to uterine rupture, massive Haemorrhage and maternal death.
\end{abstract}

Keywords: Caesarean scar pregnancy, Methotrexate, Uterine artery embolism

\section{INTRODUCTION}

Caesarean scar pregnancy (CSP) is an ectopic pregnancy implanted in the myometrium at the site of a previous cesarean section scar. It is the rarest kind of ectopic pregnancy and may lead to severe complications, such as uterine disruption and severe hemorrhage leading to even maternal death. ${ }^{1}$ Thus, it is important for early and accurate diagnosis and early management to avoid complications and preserve fertility. Several types of conservative treatment have been used: dilatation and curettage, surgical excision of trophoblastic tissues (laparotomy or laparoscopy), and local and/or systemic administration of methotrexate, bilateral internal iliac artery ligation associated with trophoblastic evacuation, and selective uterine artery embolization combined with curettage and/or MTX administration. ${ }^{4-6}$ In this paper, we describe a case of cesarean scar twin pregnancy that was treated successfully by systemically administered MTX followed by uterine artery embolization

\section{CASE REPORT}

A 30years old female, gravida 5, para 1, live 1, abortion 3, with a previous history of caesarean section with gestational age of $8 \mathrm{w} 5 \mathrm{~d} / \mathrm{DCDA}$ twin was referred from private practioner and admitted to hospital in view of low implantation of gestational sac in lower uterine corpus at the site of previous scar. On admission patient was hemodynamically stable, no complaints of bleeding per 
vaginum, Transvaginal ultrasonography: twin gestational sac noted in the lower uterine segment adjacent to scar site. (sac size upper MSD 10mm lower MSD $11 \mathrm{~mm}$ ) Uterine scar thickness $0.6 \mathrm{~cm}$ uterine cavity empty, ET $11 \mathrm{~mm}$. Good decidual reaction noted around the sac with surrounding vascularity. No adnexal mass or free fluid in the pelvis.

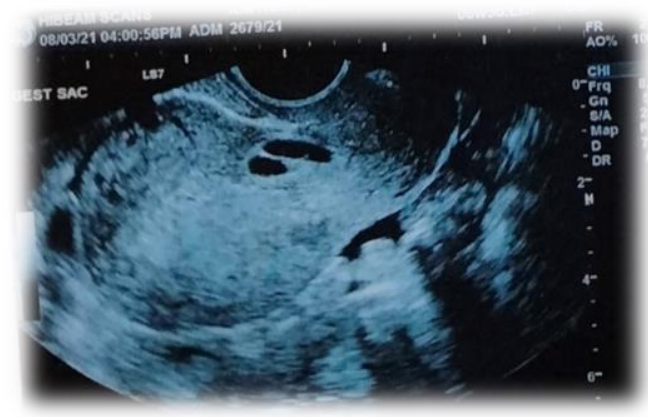

Figure 1: Day of admission.

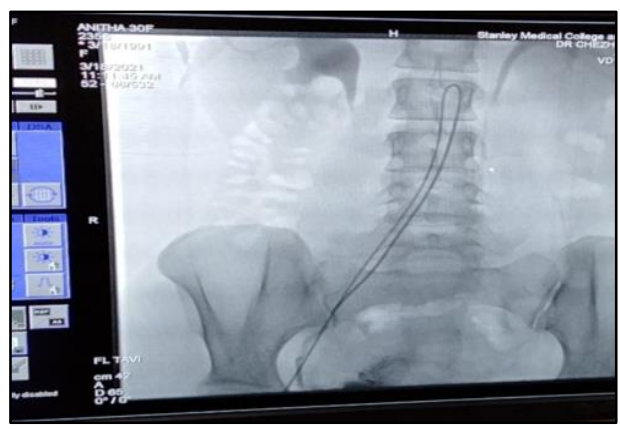

Figure 2: During embolization catheter passing through trans femoral route.

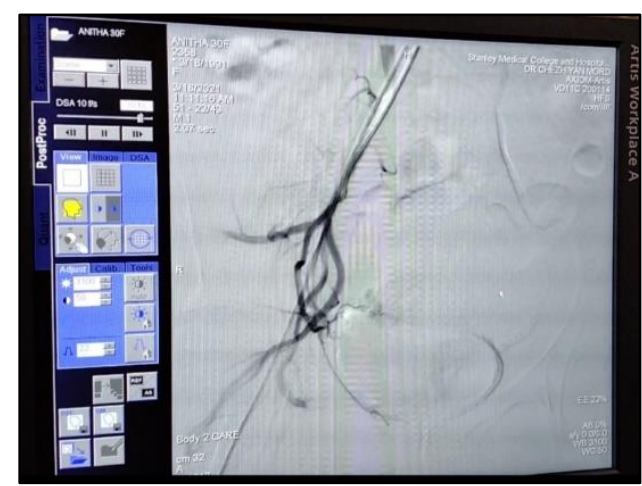

Figure 3: Uterine artery on right side.

Routine Blood investigations -normal, beta Hcg was 46,777(D1), these findings were compatible with a caesarean scar twin pregnancy. The patient was counselled regarding her management options of a twin scar pregnancy and had opted for medical management. She received a first dose (Day 0) of methotrexate $50 \mathrm{mg}$ intramuscularly. Next day after administration she developed mild spotting $\mathrm{P} / \mathrm{V}$. She was kept under observation and vitals monitoring. A serum beta hcg level on day 4 was 41545 . As there was not much decrease in beta hcg levels and in TVS there is no significant reduction in size of gestational sac, hence planned for uterine artery embolization. Uterine artery embolization procedure was done by interventional radiologist.

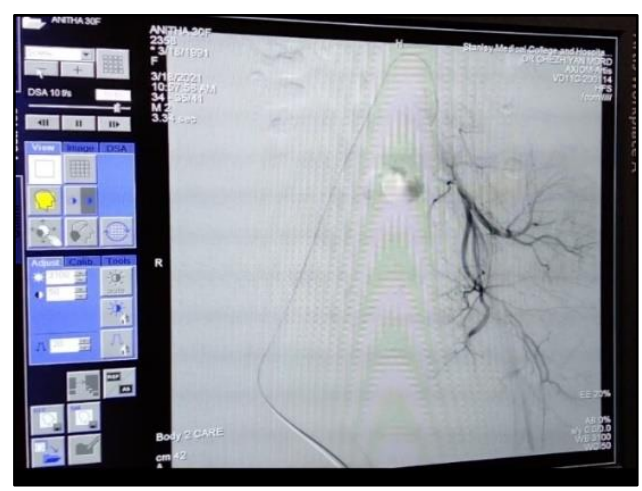

Figure 4: Post embolization, reduced blood flow to uterine artery on left side.

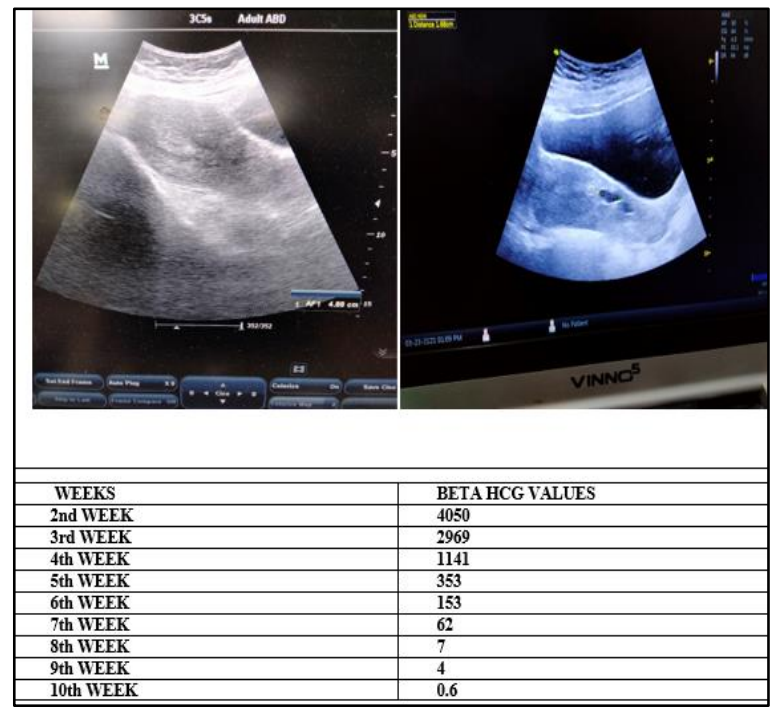

Figure 5: Postembolization ultrasound images.

\section{Uterine artery embolization procedure}

Under strict aseptic precaution with local anaesthesia, through transfemoral approach, using cobra catheter angiogram of each internal iliac artery was done (Figure 2).

Each uterine artery was dilated, tortuous and hypertrophic. each uterine artery was super selectively catheterised and embolized using gel foam slurry, till standing column is noted. Post embolization angiogram (Figure 3, 4) showed complete embolization. Post procedure events uneventful. Beta HCG on day 7 was 11417 . The sac size was reduced and beta hcg levels were falling down. Hence, the patient was discharged and follow up with beta hcg level weekly (Table 1). 


\section{DISCUSSION}

The increasing rate of caesarean sections in the two last decades has brought into light a set of complications that were not so frequent in the past, including caesareans scar pregnancy. This condition is defined as a gestation completely surrounded by myometrium and fibrous tissues of the caesarean section scar and separated from endometrium cavity and endocervical canal. ${ }^{7}$ The first case was reported in 1978 (Larsen and Solomon) as a postabortal haemorrhage due to what the authors called a uterine scar sacculus. ${ }^{8}$ Since then, cases have been reported leading to a better understanding. The possible incidence of this type of ectopic pregnancy ranges from $1 / 1800$ to $1 / 2200$ pregnancies. ${ }^{9}$ The pathophysiology of caesarean scar pregnancy remains to be established, but it is possible that the conceptus penetrates the myometrium through a microscopic dehiscent tract of the caesarean scar or the gestational sac implantation occurs in a poor healed caesarean section scar. ${ }^{3}$ It may also result from a defect in the endometrium caused by trauma created by procedures in assisted reproduction technique. ${ }^{10}$ The natural history of this condition remains unclear, it may result in a pregnancy that loses its vascular connections while growing, thus causing a spontaneous abortion, or it may continue to grow gaining new stronger vascular connections ending into a low-lying adherent placenta with or without invasion of surrounding organs. ${ }^{11}$ Early diagnosis is thus important to avoid serious complications. The most common symptom is painless vaginal bleeding that may be massive. Since there is no specific clinical sign of the CSP, endovaginal ultrasonography and color flow Doppler are essential for diagnosis. The sonographic criteria for diagnosis are: empty uterus and empty cervical canal, of the sac in the anterior wall of the isthmic portion, a discontinuity on the anterior wall of the uterus demonstrated on a sagittal plane of the uterus running through the amniotic sac, absent or diminished healthy myometrium between the bladder and the sac, high velocity with low impedance peritrophoblastic vascular flow clearly surrounding the sac is proposed in Doppler examination. ${ }^{12,13}$ Miscarriages (abortion and missed abortion) and cervicoisthmical pregnancies can be sources of confusion in the diagnosis of CSP. Ultrasonography is a precious diagnostic instrument to differentiate these conditions. The differentiating points between CSP and cervicoisthmical pregnancy include the absence of healthy uterine tissues between the sac and the bladder. ${ }^{12}$ Because of the rarity of the CSP, there are no optimal lines for therapy. Treatment modalities are either medical or surgical and are sometimes combined. The surgical approach includes radical and conservative procedures. The radical procedure consists in hysterectomy when the uterus is ruptured or if bleeding is uncontrollable. The conservative procedure includes: evacuation of the pregnancy and repair of the uterine defect by laparotomy or laparoscopy, dilatation and curettage and excision of trophoblastic tissues using laparotomy or laparoscopy and bilateral hypogastric artery ligation associated with $\mathrm{D}$ and $\mathrm{C}$ under laparoscopic guidance. , $3,14,15$ The medical treatment consists of MTX administration locally or systemically some authors combine MTX injected into the sac and potassium chloride injected locally into the fetal heart. ${ }^{13,17,18}$ The medical treatment requires a prolonged follow-up (the hCG level takes up to 4 months to return to normal) and implies a high cost. ${ }^{19}$ Bleeding may occur following the MTX injection as in the reported case, which may require surgical intervention. Failure of pregnancy resorption and persistance of a relatively large gestational sac may imply a dilatation and curettage or a laparoscopic intervention. Another important issue is the condition of the uterine scar left after medical treatment and its subsequent behaviour in future pregnancies (dehiscences are reported)20. Another treatment possibility is the uterine artery embolisation UAE which is widely accepted as a conservative treatment in postpartum hemorrhage, in uterine fibroids, it is also considered as the best method to prevent massive bleeding during $\mathrm{D}$ and $\mathrm{C}$ for cervical pregnancy. ${ }^{5,7,14}$ Although UAE seems to be promising in treating stable cases, it's not recommended as a primary line therapy. In our case, since the patient was stable and did not want to have a surgical procedure and since there was facilities for UAE, we opted for medical treatment. The immediate complications of CSP are uterine rupture, severe hemorrhage need for hysterectomy, and maternal morbidity.

\section{CONCLUSION}

In this observation, we demonstrated that viable CSP can be treated safely by systemic methotrexate injection and subsequent uterine artery embolization. Decisions on treatment options should be discussed considering gestational age, hCG levels, the presence of fetal cardiac activity, the desire of future fertility, and the experience and facilities available. Counselling patients with CSP is not easy, since there is no data about the optimum treatment. More reports are needed to rationalize the treatment modalities on this condition.

Funding: No funding sources

Conflict of interest: None declared

Ethical approval: Not required

\section{REFERENCES}

1. Herman Z, Weinraub O, Avrech R, Maymon R, RonEl Y. Bukovsky, Follow up and outcome of isthmic pregnancy located in a previous caesarean section scar. British Journal of Obstetrics and Gynaecology.1995;102(10):839-41.

2. Seow KM, Cheng C, Chuang J, Lee C, Tsai YL, Hwang JL. Methotrexate for cesarean scar pregnancy after invitro fertilization and embryo transfer: a case report. Journal of Reproductive Medicine for the Obstetrician and Gynecologist. 2000;45(9):754-7.

3. Godin PA, Bassil S, Donnez J. An ectopic pregnancy developing in a previous caesarian section scar. Fertility and Sterility.1997;67(2):398-400. 
4. Persadie RJ, Fortier A, Stopps RG. Ectopic pregnancy in a caesarean scar: a case report. 2005;27(12):398400.

5. Sugawara J, Senoo M, Chisaka H, Yaegashi N, Okamura K. Successful conservative treatment of a Cesarean scar pregnancy with uterine artery embolization. Tohoku Journal of Experimental Medicine. 2005;206(3):261-5.

6. Yang MJ, Jeng MH. Combination of transarterial embolization of uterine arteries and conservative surgical treatment for pregnancy in a cesarean section scar: a report of 3 cases. Journal of Reproductive Medicine for the Obstetrician and Gynecologist. 200348(3):213-6.

7. Yan CM. A report of four cases of caesarean scar pregnancy in a period of 12 months,Hong KongMedical Journal. 2007;13(2):141-3.

8. Larsen JV, Solomon MH. Pregnancy in a uterine scar sacculus: an unusual cause of postabortal haemorrhage. A case report, South African Medical Journal. 1978;53(4):142-3.

9. Seow KM, Hwang JL, Tsai YL, Huang LW, Lin YH, Hsieh BC, Subsequent pregnancy outcome after conservative treatment of a previous cesarean scar pregnancy. Acta Obstetricia et Gynecologica Scandinavica. 2004;83(12):1167-72.

10. Hamilton CJCM, Legarth J, Jaroudi KA. Intramural pregnancy after in vitro fertilization and embryo transfer, Fertility and Sterility.1992;57(1):215-7.

11. Al-Nazer A, Omar L, Wahba M, Abbas T, Abdulkarim M. Ectopic intramural pregnancy developing at the site of a cesarean section scar: a case report, Cases Journal. 2009;2(12):art.9404.

12. Fylstra DL, Pound-Chang T, Miller MG, Cooper A, Miller KM. Ectopic pregnancy within a cesarean delivery scar: a case report. American Journal of Obstetrics and Gynaecology. 2002;187(2):302-4.

13. Jurkovic D, Hillaby K, Woelfer B, Lawrence A, Salim R, Elson CJ. First-trimester diagnosis and management of pregnancies implanted into the lower uterine segment Cesarean section scar. Ultrasound in Obstetrics and Gynecology. 2003;21(3):220-7.

14. Tulpin L, Morel O, Malartic C, Barranger E. Conservative management of a Cesarean scar ectopic pregnancy: a case report. Cases Journal. 2009;2(8):7794.

15. Arslan M, Pata O, Dilek TUK, Aktas A, Aban M, Dilek S. Treatment of viable cesarean scar ectopic pregnancy with suction curettage. International Journal of Gynecology and Obstetrics. 2005;89(2):163-6.

16. Kung FT, Huang CW, Chen CW, Cheng YF. Cesarean scar ectopic pregnancy. Fertility and Sterility. 2006;85(5):1508-9.

17. Shufaro Y, Nadjari M. Implantation of a gestational sac in a cesarean section scar. Fertility and Sterility. 2001;75(6):1217.

18. Nagi JB, Helmy S, Ofili-Yebovi D, Yazbek, Sawyer E, Jurkovic D, Reproductive outcomes of women with a previous history of Caesarean scar ectopic pregnancies. Human Reproduction. 2007;22(7):20125.

19. Doubilet PM, Benson CB, Frates MC, Ginsburg E. Sonographically guided minimally invasive treatment of unusual ectopic pregnancies. Journal of Ultrasound in Medicine. 2004;23(3):359-70.

20. Hasegawa J, Ichizuka K, Matsuoka R, Otsuki K, Sekizawa A, Okai T. Limitations of conservative treatment for repeat Cesarean scar pregnancy. Ultrasound in Obstetrics and Gynecology. 2005;25(3):310-1.

Cite this article as: Elango SK, Nevetha K, Aruna. Successful conservative treatment of a caesarean scar twin pregnancy with systemically administered methotrexate and subsequent uterine artery embolization: a rare case report. Int J Reprod Contracept Obstet Gynecol 2022;11:979-82. 